\title{
La conciliación en la Universidad, iun asunto solo de mujeres?
}

The conciliation in the University, a matter only of women?

\author{
Alejandra Selma Penalva \\ Profesora Titular de Universidad. \\ Departamento de Derecho del Trabajo y de la Seguridad Social. \\ Facultad de Derecho. \\ Universidad de Murcia. \\ E-mail: aselma@um.es
}

\begin{abstract}
Resumen: Las dificultades de conciliar vida laboral y profesional constituyen, en la práctica, uno de los principales factores que desencadenan la desigualdad de oportunidades que hombres y mujeres presentan en el ámbito laboral y académico. Aunque se trate de un hecho que todavía muchas veces pase desapercibido, las Universidades españolas, pese a los importantes esfuerzos realizados al respecto, todavía adolecen de ciertos defectos que, de forma indirecta, lastran la carrera profesional y académica de las personas con cargas familiares, incidiendo de forma especialmente intensa sobre el colectivo femenino. En el presente trabajo se analizan algunas de las causas de desigualdad y se proponen estrategias de mejora con el fin de solventar los problemas detectados.
\end{abstract}

Palabras clave: igualdad de género, Universidad, investigación, conciliación, cuestiones pendientes.

\begin{abstract}
Work and professional life reconciling difficulties constitute, in practice, one of the main factors that causes inequality of opportunities between men and women in work and academic field. Although it is a fact that still often goes unnoticed, the Spanish Universities, despite the important efforts made in this regard, still suffer from certain defects that indirectly undermine the professional and academic career of people with family charges, having an especially impact on the female collective. In this paper,
\end{abstract}


some of the causes of inequality are analyzed and improvement strategies are proposed in order to solve the problems detected.

Keywords: gender equality, University, research, conciliation, pending issues.

\section{La conciliación en la Universidad, ¿un asunto solo de mujeres?}

\section{The conciliation in the University, a matter only of women?}

Sumario: 1. Consideraciones iniciales. 2. Dificultades de conciliación del profesorado. Los defectos de un modelo pretendidamente "igualitario". 3. Las cargas familiares del alumnado: un asunto olvidado. 4. Cuestiones para reflexionar. 5. Bibliografía

\section{Consideraciones iniciales}

Menos sexenios, menos y más tardías cátedras y menor desempeño de cargos académicos por parte de las docentes de sexo femenino son los resultados más llamativos que arroja una primera aproximación a las entrañas de las Universidades públicas, pero no los únicos ${ }^{1}$. La tasa de natalidad, ya por sí reducidísima en territorio español, alcanza mínimos entre las profesoras de universidad que, además, sobrellevan la triste carga de ser un colectivo con una de las edades medias de maternidad más tardías de Europa $^{2}$, lo que sin duda constituye una clara muestra de la dificultad que, a la vista de los criterios vigentes, conlleva la estabilización laboral en este ámbito profesional $^{3}$. A estos efectos, los datos son muy claros: según el análisis publicado por la CNEAI, aunque las mujeres superan a los hombres en porcentaje de éxito en la franja de uno y dos sexenios, se detecta una clara mayoría masculina a partir del tercer

\footnotetext{
${ }^{1}$ Tal y como exponen LÓPEZ ANIORTE, M.C, GARCÍA ROMERO, M.B, y FERRANDO GARCÍA, F.M. (2014), "Propuesta para la evaluación de la calidad de la investigación en el ámbito del Derecho del Trabajo y de la Seguridad Social, incluyendo una perspectiva de género", Libro resúmenes X Foro Internacional sobre la Evaluación de la Calidad de la Investigación y la Educación Superior (Coord. RAMIRO SÁNCHEZ y RAMIRO SÁNCHEZ), Ed. Universidad de Granada, Granada, págs. 100 y ss.

${ }^{2}$ En el ámbito de la docencia universitaria, las profesoras de universidad presentan actualmente, una edad media de nacimiento de su primer hijo muy superior a la ya por sí elevada media española (37 años frente a los 31 años registrados con carácter general).

${ }^{3}$ El complejo tema de la estabilización profesional en el entorno universitario, ya se analizó en AAVV (1996), "Mujeres y hombres en la ciencia española. Una investigación empírica", Ministerio de Trabajo y Asuntos Sociales, Secretaría General de Políticas de Igualdad, Instituto de la Mujer, Madrid. A las consideraciones que en aquel momento se pusieron de manifiesto, hay que añadir la ralentización de la estabilización profesional generada por la inclusión de nuevas categorías profesionales intermedias a raíz de la entrada en vigor de la vigente LOU.
} 
sexenio, dato que demuestra de forma contundente la mayor intensidad con la que la atención de las cargas familiares repercute sobre personas de sexo femenino. De la misma forma, según los últimos datos publicados por el Ministerio, las mujeres representan el 40\% de los Profesores Titulares de Universidad, pero solo ocupan el 20\% de los puestos correspondientes al cuerpo de Catedráticos ${ }^{4}$.

La conclusión lógica a la que conducen todos estos datos es obvia: como en todos los ámbitos sociales, también en las Universidades públicas existe hoy una intensa penalización por maternidad. Y es que, a pesar de ser, por lo general, centros pioneros en lo que respecta a la elaboración de planes de igualdad, implementación del lenguaje no sexista, o creación de guarderías universitarias, todavía existen importantísimos lastres que no se ha sabido combatir. En el presente trabajo se enumeran algunos de ellos con la intención de generar en el lector una reflexión crítica acerca de lo que es realmente (y lo que podría llegar a ser) la igualdad de género en el ámbito universitario.

A estos efectos, es importante incidir en que, el tipo de discriminación que se constata en este entorno académico, en la inmensa mayoría de ocasiones, acaece de forma indirecta: esto es, a partir de una conducta, trámite o exigencia aparentemente fundamentada en presupuestos neutros, con la que, en la práctica, se consigue desencadenar un efecto particularmente gravoso sobre uno de los sexos, en este caso, sobre el femenino. Por ese motivo, de las prácticas discriminatorias que se denuncian a continuación, ninguna de ellas está motivada por cuestiones de género en sí mismas, sino por las vinculaciones biológicas y sociales que conectan género y maternidad, y género y atención de las cargas familiares. $\mathrm{Y}$ es precisamente en este campo donde todavía queda un largo recorrido para poder alcanzar la plena igualdad de género, lo que exige una reivindicación clara y contundente por parte de la comunidad universitaria.

\section{Dificultades de conciliación del profesorado. Los defectos de un modelo pretendidamente "igualitario"}

Como nuestra jurisprudencia más reciente se ha ocupado insistentemente de reiterar, constituye hoy en día un hecho notorio que, todavía en pleno siglo XXI, son las

\footnotetext{
4 Curiosamente, las mujeres ocupan el $60 \%$ de los puestos de investigación y docencia en las Universidades públicas a los 30 años de edad, pero este porcentaje se invierte al alcanzar los 40 años. A estos efectos, resulta muy significativo comprobar el ínfimo porcentaje de sujetos que acceden a la condición de profesor titular de Universidad (y con ello, a la funcionarización en el ámbito universitario), antes de alcanzar los 40 años de edad, según cifras publicadas por el propio Ministerio de Educación, Cultura y Deporte. http://www.educacionyfp.gob.es/servicios-al-ciudadano-mecd/dms/mecd/servicios-alciudadano-mecd/estadisticas/educacion/universitaria/estadisticas/personal-universitario/NOTA-EPU-

2015-2016.pdf
} 
mujeres y no los hombres las que asumen, con una responsabilidad más intensa, la atención de las cargas familiares, en detrimento de las oportunidades de ocupación y promoción profesional ${ }^{5}$. Por ese motivo, todo aquello que suponga un obstáculo a la conciliación de la vida personal y laboral, puede considerarse un factor desencadenante de la desigualdad de trato y oportunidades entre mujeres y hombres.

Esta máxima, que resulta aplicable a todos los ámbitos sociales y profesionales, resulta también plenamente aplicativa al contexto universitario, tal y como demuestran las cifras anteriormente señaladas. Y es entonces cuando la paradoja resulta evidente: ¿cómo puede ser que, en un contexto profesional caracterizado por su alto margen de flexibilidad presencial, existan dificultades de conciliación? ¿Por qué existe una brecha de género tan marcada? ¿Dónde radica el problema? Un análisis crítico del contexto universitario permite detectar diversos frentes de desigualdad, todavía abiertos, y sobre los que, por el momento, no hay perspectivas de cambio:

El primero de ellos, reside, obviamente, en la dificultad de conciliación de la vida familiar y laboral que llevan aparejadas las estancias de investigación que exige el sistema de acreditación vigente marcado por la ANECA para todas las categorías universitarias y para todas las ramas de conocimiento. El segundo, se encuentra sin duda en las dificultades de conciliación que presentan la mayor parte de los horarios lectivos, y las escasas (y mal recibidas) estrategias puestas en marcha en las Universidades públicas con el fin de permitir a su personal compatibilizar con mayor facilidad las obligaciones docentes y las familiares -dificultad que en la práctica se agrava debido a la elevada distancia que, por lo general, separa los campus universitarios de los núcleos urbanos-. El tercer factor de desigualdad, y no por ello menos importante, es la ausencia total de referencia normativa que permita dilucidar qué ocurre con el desempeño de un cargo académico cuando la persona en cuestión disfruta de una baja por maternidad (hoy denominada por cuidado de hijos), o de una situación de reducción de jornada o excedencia por cuidado de hijos. Por su importancia, cada uno de estos tres temas apuntados merece una explicación detallada.

\footnotetext{
${ }^{5}$ De forma rotunda, la SAN (Sala de lo Social) de 13 de noviembre de 2013 (AS/2013/3023), reconoce expresamente que se parte "de una premisa que no está cuestionada por constituir un hecho notorio. Se trata de la afirmación relativa a que los derechos de conciliación de la vida familiar y la protección de la maternidad y el derecho de lactancia están mayoritariamente ejercitados por mujeres". Aunque los hechos notorios no necesitan ser probados, existen hoy en día múltiples datos estadísticos que permitirían confirmar dicha circunstancia. Así, al respecto, véase MEIL LANDWERLIN, G. (2011), "El uso de los permisos parentales por los hombres y su implicación en el cuidado de los niños en Europa", Revista latina de sociología, $\mathrm{n}^{\circ}$. 1, pág. 8 del soporte informático.
} 
Así pues, por lo que a las estancias de investigación se refiere, los criterios de acreditación exigidos por la ANECA para todas las categorías profesionales incluyen la valoración de estancias de investigación en centros de recocido prestigio, preferiblemente internacionales. Debe insistirse en que, esta exigencia, además de dar lugar a un fenómeno de movilidad internacional de trabajadores sin respetar ninguna de las garantías que exige el art. 1.4 ET en favor del trabajador temporalmente desplazado (tema con importantes connotaciones legales $^{6}$ que merecería ser analizado con el detenimiento que merece en un trabajo independiente ${ }^{7}$ ), desencadena unas dificultades de conciliación muchas veces insalvables, cuyos efectos adversos, en la práctica, sufren con más fuerza las mujeres que los hombres.

Pero no solo eso. En la práctica, a la complejidad de atender las obligaciones familiares mientras se realiza una estancia de investigación, se une la carga económica que ello implica, lo que en definitiva repercute en la calidad de vida del hogar familiar ${ }^{8}$. Adviértase que la Disposición adicional décima de la LOU expresamente indica que "Los poderes públicos promoverán mecanismos de movilidad entre las Universidades y otros centros de investigación, con sus correspondientes programas de financiación (...)". A pesar de esta genérica proclamación, nadie discute que, en la práctica, son muy pocos los investigadores provenientes de Universidades públicas españolas los que obtienen financiación suficiente para cubrir íntegramente los gastos que genera el desplazamiento a otra Universidad distinta a la propia y preferiblemente extranjera, pese a que quedan obligados a realizar este tipo de estancias de investigación si desean continuar su carrera universitaria. Se trata de inconvenientes que pueden llevar a una situación desesperación al osado docente al que se le ocurra asumir responsabilidades

\footnotetext{
${ }^{6}$ Pues, aunque por el momento no se tenga en cuesta esa importantísima cuestión, la movilidad del profesorado universitario realizada a través de estancias de investigación da lugar a un supuesto claro de movilidad temporal de trabajadores, nacional o internacional según corresponda, y como tal, debe ajustarse a los presupuestos exigidos en la legislación laboral al respecto, con los que se intenta dotar de un régimen jurídico especialmente protector al trabajador desplazado, que por el momento se incumple flagrantemente en el ámbito universitario. Se trata de un tema que se analiza con detenimiento en SELMA PENALVA. A., "La discriminación por maternidad y conciliación en el ámbito universitario", FÉMERIS. Revista Multidisciplinar de Estudios de Género. Universidad Carlos III, nº. 2, Volumen 4, nº. 2, 2019, págs. 132-153.

7 Sobre el interesantísimo y complejo tema de la movilidad internacional de trabajadores, véase GALIANA MORENO, J.M. (2015), "Apuntes sobre el tráfico laboral externo en la jurisprudencial de Tribunal Supremo"; en AAVV, "El Estatuto de los Trabajadores en la jurisprudencia del Tribunal Supremo: estudios dedicados al catedrático y magistrado Don Antonio Martín Valverde" (coord. Joaquín García Murcia, Manuel Ramón Alarcón Caracuel), Madrid, Tecnos, Capítulo III.

${ }^{8}$ La situación se puede agravar al máximo en determinadas Universidades en las que, por acuerdo de Consejo de Gobierno, o por previsión incluida en el convenio colectivo aplicable, como ocurre, por ejemplo, en la Universidad de Murcia, posiblemente con ánimo disuasorio, se determina la reducción de un $20 \%$ de la retribución del profesor universitario a partir del tercer mes de estancia.
} 
familiares antes de alcanzar la tan deseada estabilización laboral, pues no se puede olvidar que, respecto a las categorías de ayudante y ayudante doctor (modalidades contractuales laborales con una duración máxima de cinco años), el acceso a una categoría profesional superior resulta imprescindible si se quiere mantener la relación laboral con la Universidad. Así las cosas, se hace imprescindible potenciar y premiar desde la ANECA la realización de otros méritos profesionales, también indicativos de la solvencia investigadora del profesor en cuestión, pero que no impliquen movilidad geográfica $\mathrm{y}$, por lo tanto, que no generen dificultades añadidas en materia de conciliación de la vida familiar y laboral. Y es que, salvo especialidades y destinos muy concretos, en un entorno digital, en el que la comunicación interuniversitaria puede realizarse por vía informática, y en el que el acceso a los recursos bibliográficos en la mayoría de los casos se realiza, de forma muy ágil, a través de bases de datos online, ha de admitirse que, la posibilidad de realizar un desplazamiento físico, por sí solo, ya no tiene por qué considerarse indicador destacado de la solvencia académica del sujeto que las realiza.

Por lo que respecta a la adaptación de los horarios académicos por motivos de conciliación, debe admitirse en primer lugar que el principal inconveniente que afecta al personal universitario es precisamente el mismo que incide sobre los restantes trabajadores de nuestro país, tanto si prestan servicios como trabajadores por cuenta ajena, como empleados públicos o como trabajadores autónomos: los servicios públicos existentes de atención a menores de edad y a personas dependientes en nuestro país resultan claramente insuficientes para atender las importantísimas demandas sociales, no solo por la escasez de guarderías, residencias y centros de día de personas mayores de titularidad pública, sino por el carácter tan limitado que hoy en día tiene la escolarización pública. Y es que, a ésta, solo pueden acceder mayores de tres años, durante menos de diez meses al año. De la misma forma, tampoco los horarios escolares (que, como máximo, abarcan el periodo diario comprendido entre las $9.00 \mathrm{~h}$ y las 17.00 h.) coinciden por lo general con los horarios laborales, obligando en muchos casos a uno de los miembros de la pareja a sacrificar oportunidades laborales o a recurrir, previo pago, a personal de apoyo o a actividades complementarias, con el fin de poder compatibilizar sus obligaciones familiares con las laborales. Pero al margen de los obstáculos a los que se enfrenta la población activa en general, la yuxtaposición de obligaciones docentes con investigadoras genera problemas de conciliación específicos dentro del colectivo de profesores de Universidad. 
$\mathrm{Al}$ respecto, se ha de ser consciente que la flexibilidad que, en la mayor parte de ocasiones, reporta la carrera universitaria, hace muy infrecuente que el profesorado solicite ni reducción de jornada ni situación de excedencia por cuidado de hijos o familiares, que se suelen reservar para casos extremos. Por lo tanto, en la práctica, la mayor parte de solicitudes de conciliación (salvo quizá, las formuladas por el personal de administración y servicios) únicamente estarán destinadas a conseguir una mera adaptación de los horarios de trabajo, con el fin de facilitar la atención de la familia.

Precisamente a estos efectos, conviene insistir en una importantísima circunstancia que está pasando desapercibida: las obligaciones académicas comprenden no solo la docencia sino también la investigación, factor que aporta un enorme potencial a la hora de racionalizar las horas de presencia en los centros de trabajo de las Universidades públicas que no existe en otros ámbitos productivos. Pero si esto es así, ¿por qué por el momento, en el entorno universitario, no se han explorado todas las posibilidades que este ámbito ofrece? La práctica está demostrando que en nuestras Universidades existe un gran desinterés en abordar estas cuestiones. Posiblemente sea la escasa tasa de natalidad en el entorno universitario, la que llevan a los docentes, en muchos casos, a resignarse con la situación existente, pero ¿por qué no cambiar las cosas? Con el fin de permitir que la conciliación de las cargas familiares no suponga un factor de preocupación entre los miembros de la comunidad universitaria ¿cuántas titulaciones han optado por comenzar sus clases a partir de las 9.15 h.? ¿Cuántos Másteres Universitarios se imparten actualmente en horario de mañana ${ }^{9}$ ? Hoy en día, ¿existe alguna Universidad española que haya adaptado los horarios docentes para hacerlos coincidir con los horarios escolares? ¿Alguno de los Departamentos universitarios ha otorgado preferencia a los docentes con cargas familiares a la hora de elegir asignaturas y grupos o, por el contrario, sigue prevaleciendo el sistema tradicional basado en la elección por jerarquía y antigüedad? ¿Por qué ningún convenio colectivo de ninguna Universidad pública, hasta el momento, ha establecido un sistema de reducción de carga docente para el profesorado con hijos menores de tres años, con familia numerosa o con personas con discapacidad a su cargo ${ }^{10}$ Sin duda se trata de

\footnotetext{
${ }^{9}$ Una de las pocas excepciones la encontramos en el Máster universitario en mediación e intervención social, impartido en la Facultad de Psicología de la Universidad de Sevilla, de 9 a 14 horas, o en los Másteres en Ingeniería de Caminos, Canales y Puertos y en Ingeniería Química que imparte la Universidad de Alicante. Al respecto existe una importante cuestión sobre la que reflexionar: ¿tan alta es, realmente, la tasa de ocupación laboral del alumnado de los másteres universitarios que hace aconsejable impartirlos exclusivamente en horario de tarde?

10 En general, la escasa atención que los convenios colectivos suscritos, no solo por Universidades públicas, sino, en general, por empresas y entidades españolas, han estado prestando a la igualdad de
} 
cuestiones que hay que empezar a estudiar con detenimiento si se quiere alcanzar una verdadera igualdad de género en el ámbito universitario.

Pero no solo eso. Una vez asignadas las asignaturas y grupos, ¿cómo resuelven los Centros las peticiones de adaptación horaria del profesorado? A estos efectos se ha de concienciar al profesorado que el sistema previsto de elección de asignatura y grupo, así como el de atribución de horarios debe prever la necesidad de conciliación, estableciendo un elenco claro de actuaciones y derechos, pues en caso contrario, se tratará de temas que se seguirán dejando al mutuo acuerdo y la buena voluntad de los implicados, no siempre fiables. A estos efectos parece lógico entender que las reuniones de horarios vuelven a ser el instrumento más adecuado para satisfacer las preferencias personales del profesorado de la forma más rápida posible, teniendo en cuenta que, hoy en día, el solapamiento de clases y la existencia de cargas familiares han de ser los factores que ordenen la preferencia en la elección de horario entre los interesados.

Desde otro punto de vista, se ha de incidir en que la investigación ha de considerarse un factor esencial para medir la calidad del profesorado universitario y con ella, de los centros docentes. Pero, si esto debe ser así, ¿por qué está siendo injustamente infravalorada en comparación con otro tipo de actividades académicas y de gestión muchas veces superfluas y perfectamente prescindibles? Y es que si es ya complicado compatibilizar un alto nivel de investigación con la atención de las cargas familiares, más lo es cuando, en el sistema vigente, subyace la idea malintencionada de que la investigación es un mero plus, una carga voluntariamente asumida por los profesores, ajena a lo que en los últimos años que está considerando actividad académica esencial que no es ya la docencia, sino la pequeña gestión y burocratización de los procesos académicos que es capaz de absorber infinidad de horas de trabajo. Hasta que no tomemos conciencia de que investigación y docencia constituyen un binomio inseparable dentro de la carrera universitaria, presentando un peso idéntico en el elenco de obligaciones académicas, de que la flexibilidad horaria, como ocurre con todo trabajo intelectual, es esencial para mantener un buen nivel de investigación, de que la retribución de los sexenios es mínima en comparación con el esfuerzo requerido, y de que, a mayor nivel y producción investigadora, se asegura mayor solvencia en la faceta docente de la persona, las Universidades públicas no podrán ni siquiera soñar con

género, se pone de manifiesto en AAVV (2016), "El principio de igualdad en la negociación colectiva", SÁNCHEZ TRIGUEROS (dir.), KAHALE CARRILLO y VELASCO PORTERO (coord.), Colección Informes y Estudios. Serie Relaciones Laborales, Ministerio de Trabajo y Asuntos Sociales, Madrid. 
ocupar uno de los primeros puestos en los rankings europeos, ámbito en el que son ya conocedores de que una excesiva burocratización, como la que actualmente domina al modelo español, es la mayor enemiga de la calidad académica.

Respecto a la última de las tres cuestiones que se querían poner de manifiesto en este apartado, la relativa a la menor frecuencia con que todavía hoy las mujeres desempeñan cargos académicos en el ámbito universitario, en comparación con sus compañeros varones ${ }^{11}$, son varios factores la que la explican, por lo menos, en abstracto:

Por una parte, la menor frecuencia estadística de catedráticas que de catedráticos lleva a seleccionar a personas de género masculino para desempeñar algunos cargos académicos que, por su nivel y responsabilidad, suelen reservarse para las personas de mayor categoría profesional (Rector, Decano, Director de Departamento, Director de Escuela universitaria, Defensor universitario, etc.). Por otra, la excesiva burocratización que muchas veces conlleva el ejercicio de estos cargos, con la consiguiente pérdida de la ya poca flexibilidad horaria que puede todavía reportar la carrera académica, unido al reducido importe del complemento por cargo académico que este tipo de cargos implica, llevan a personas con cargas familiares a rechazar las propuestas que, en este sentido pudieran planteárseles, lo que en definitiva conlleva una menor presencia femenina en los puestos que exigen mayor nivel, dedicación y responsabilidad, conformarse, en su caso, con un cargo académico menor (como Secretaria de Departamento, de Escuela Universitaria o la coordinación de un Máster, por ejemplo) ${ }^{12}$.

Un signo claramente demostrativo de que la presencia femenina en los cargos académicos es muy inferior a su presencia numérica entre el colectivo de docentes universitarios lo aporta el siguiente dato: ninguna universidad española ha previsto expresamente un sistema de sustitución temporal en el desempeño del puesto por motivos de maternidad o paternidad. Pero ¿es que ningún Rector/a, Vicerrector/a, Director/a de Departamento o Decano/a ha tenido un hijo durante el periodo de elección? ¿Se paraliza la actividad de la entidad en cuestión hasta la plena

\footnotetext{
${ }^{11}$ Resultado de los datos recopilados por la Fundación CYD y publicados en los medios de comunicación htt://www.google.es/amp/s/cadenaser.com/ser/2018/03/02/sociedad/1520005123_473823.amp.html

${ }^{12}$ Se trata de porcentajes que han hecho públicos algunas de las Universidades españolas, como es el caso de la Universidad Complutense de Madrid, https://www.publico.es/sociedad/complutense-universidadmujeres-gobernada-hombres.html. Otro dato que sería oportuno conseguir en las Universidades públicas es la duración media en el desempeño de estos puestos de responsabilidad, pues isuelen las mujeres repetir mandato, o se conforman, en caso de ser elegidas con un único mandato, rechazando la posibilidad de reelección? Se trata de datos que todavía no han sido individualizados y desglosados por nuestras Universidades, a pesar de que aportarían una importantísima información sobre factores indirectos de desigualdad que todavía subyacen en el entorno universitario.
} 
reincorporación de la persona que la dirige? ¿Se llega a acuerdos informales de sustitución que no dejan reflejo oficial? ¿Se puede designar, "interinamente”, a otra persona de confianza para que desempeñe estas funciones a la espera de la reincorporación de su ocupante original? O, por el contrario, ¿se fuerza tácitamente a una renuncia de tales puestos cuando las necesidades familiares se acentúan? ¿Tan bajísima es la tasa de natalidad en la Universidad, que nadie ha exigido lo que no deja de ser un derecho básico de los empleados, independientemente del carácter laboral o funcionarial de su relación o de la naturaleza pública o privada de su empleador?

Debe insistirse en un hecho que, aunque obvio, muchas veces queda injustamente olvidado: a pesar de que los derechos de conciliación afecten por igual a hombres y mujeres, el proceso de desgaste físico derivado del embarazo y el parto es exclusivamente femenino, por lo que serán más ellas que ellos, las que se vean abocadas a renunciar a puestos de responsabilidad con el fin de disfrutar su periodo de baja sin incidencias. La única forma posible de solucionar este tipo de problemas es concienciando a los interesados de que, durante el periodo de baja maternal o paternal, el sujeto en cuestión, tiene no solo el derecho, sino también la obligación de suspender totalmente su prestación de servicios, y no solo su presencialidad en el centro de trabajo, por lo que no puede continuar realizando las labores de gestión desde su domicilio a través de internet, como muchas veces ocurre en el ámbito universitario. Impidiendo el descanso profesional total cuando el sujeto se encuentra en situación de baja, no solo se genera un riesgo psicosocial, pudiendo desencadenar fuertes episodios de estrés totalmente contrarios a la prevención de los riesgos profesionales, sino que también, se comete una infracción muy grave de las obligaciones empresariales en materia de Seguridad Social, fuertemente sancionable para las Universidades que no detecten y eviten estos episodios. Por ese motivo, las Universidades deben tomar conciencia de que, permitiendo la actividad de un perceptor de prestaciones de la Seguridad Social que, en principio, son incompatibles con el trabajo, como son las bajas por maternidad o paternidad, o por IT, aunque únicamente se trate de una tolerancia tácita de un trabajo prestado en forma virtual sin atención presencial del alumnado, se transgrede seriamente la normativa laboral, y se comete una infracción administrativa. Ahora bien, ¿cómo se impide esto? ¿Se ha de responsabilizar a los sujetos que desempeñan cargo académico de la necesidad de "desatender" temporalmente, durante su baja, unas tareas que desempeñan en beneficio de la comunidad universitaria? No se puede olvidar que, en muchos casos, esta atención de responsabilidades en periodos de baja se realiza de 
forma bienintencionada pues, al no haberse previsto una fórmula rápida y eficaz de sustitución, se intenta con ello mantener la atención del alumnado, evitando sobrecargar a compañeros de trámites con los que no están familiarizados.

Pese a su aparente sencillez, no es fácil corregir estas situaciones, principalmente porque, en el modelo actual de gestión universitaria no es nada fácil determinar qué persona desempeñará temporalmente las funciones de sustitución. Y es que mientras existen bolsas de contratación destinadas a cubrir temporalmente las obligaciones docentes del profesorado universitario en situación de baja, no se ha articulado hasta ahora un proceso útil y rápido de sustitución de las responsabilidades derivadas del desempeño de un cargo académico. Ante esta situación, surgen las siguientes dudas ¿deberá ser el mismo sustituto proveniente de la bolsa de empleo el que asuma temporalmente unas funciones de responsabilidad inherentes al desempaño de un cargo académico con las que no está familiarizado y que muchas veces, al implicar el ejercicio de fe pública, exigen ser desarrolladas por funcionarios? ¿Ha de ser el doctor más antiguo de los integrantes en el mismo equipo rectoral o decanal, comisión académica o patronato rector el que asuma circunstancialmente las funciones de dirección? Y si esto es así, ¿no se está sobrecargando de trabajo al miembro del equipo que, temporalmente, deberá asumir sus propias funciones, más las que desarrollaba la persona a la que está sustituyendo? ¿Se trata de una situación sobrellevable durante largos periodos de tiempo, como puede ser una suspensión del contrato por IT derivada de embarazo seguida de baja por maternidad o una situación de IT de larga duración? ${ }^{13}$. Aunque un sistema de atribución temporal de tareas a un sustituto resultaría perfectamente lógico y compatible con las necesidades de descanso y conciliación que los supuestos de baja requieren, para poder ser aplicado con rapidez en nuestras Universidades sería preciso ir reformando progresivamente los estatutos de los centros y departamentos con el fin de incluir una cláusula dedicada a clarificar el régimen de sustitución que deberá aplicarse,

\footnotetext{
13 Ante situaciones de esta índole, parece razonable diferenciar la sustitución de las obligaciones docentes, de la sustitución de las obligaciones administrativas inherentes al desempeño de un cargo de gestión. Y es que mientras las primeras pueden cubrirse a través de una bolsa de contratación convocada al efecto, las segundas, por especialización y responsabilidad que implican, deben quedar atribuidas a un sujeto que mantenga con la Universidad una vinculación permanente, como forma de garantizar la calidad en la prestación del servicio. También parece razonable que la persona que asuma temporalmente estas funciones de dirección, no compatibilice durante su periodo de sustitución, estas tareas con el desempeño de otro cargo académico, para no sobrecargar en exceso de tareas a un único sujeto, aunque ello implique una rotación temporal de los cargos académicos de varias personas (por ejemplo, en caso de sustitución temporal de un decano o decana de centro, buscando que su sustitución temporal la realice el vicedecano más antiguo, mientras que a este a su vez lo puede sustituir temporalmente un miembro de la junta, con vinculación permanente y a tiempo completo con la Universidad, que hasta el momento no tuviese asignado ningún cargo académico).
} 
llegado el momento, articulando un sistema de sustitución que sea respetuoso con la especial confianza y responsabilidad que siempre ha de asumir la persona que ocupe este tipo de cargos, aunque sea temporalmente. Hasta que eso no ocurra, cualquier proceso de sustitución que se idee será lento, complejo e ineficaz. Y lo que es peor, dará lugar a crear el contexto propicio para que el sujeto de baja, haciéndose un flaco favor a sí mismo y a la propia Universidad, siga atendiendo sus antiguas responsabilidades desde casa: ¿esos son realmente los efectos que provoca la flexibilización de la presencialidad en el ámbito universitario?

\section{Las cargas familiares del alumnado: un asunto olvidado}

Aunque nuestras Universidades suelen poner especial cuidado en prevenir la violencia de género y el acoso sexual en las aulas, por el momento, apenas se demuestra interés en valorar las oportunidades de conciliación de la vida familiar y laboral que los horarios lectivos permiten al alumnado universitario.

Pese a que, en números globales, la tasa femenina de matriculación y de rendimiento en el conjunto de las Universidades españolas es superior a la masculina ${ }^{14}$, todavía subsisten ciertas costumbres universitarias relacionadas con la impartición de la docencia que nunca van a superar una valoración crítica realizada con perspectiva de género. Basta una primera aproximación para detectar que ciertas prácticas académicas, aunque sea de forma velada, introducen factores de desigualdad de trato que inciden con más fuerza sobre personas de sexo femenino y que, llegado el caso, pueden motivar no solo la obtención de una calificación final más baja de la media, sino también el abandono de los estudios o la desmotivación para iniciarlos. Y es que sí, en la práctica, la atención de las cargas familiares, que estadísticamente recae, en todos los ámbitos, sectores y estratos sociales, con más fuerza sobre las mujeres que sobre los hombres, también las alumnas universitarias quedarán afectadas por esta premisa. Hay que insistir en que la noción de atención de cargas familiares no se limita únicamente a la atención de descendientes menores de 12 años. Hermanos, padres o abuelos que, por razón de edad, enfermedad o discapacidad, no puedan valerse por sí mismos temporal o permanentemente, también dificultan, en muchos casos, la asistencia periódica a clase del alumnado femenino. Es precisamente entonces cuando se han de saber identificar

14 Tal y como demuestran los últimos datos estadísticos publicados por el Ministerio de Educación, Cultura y Deporte. https://www.mecd.gob.es/dms/mecd/servicios-al-ciudadano$\mathrm{mecd} /$ estadisticas/educacion/universitaria/datos-cifras/datos-y-cifras-SUE-2015-16-web-.pdf 
los riesgos inherentes a los sistemas de evaluación continua ${ }^{15}$. Y es que, aunque en principio ideados para facilitar la superación de las asignaturas respecto al alumnado que asiste con regularidad a clase, no se puede negar que perjudicarán al sujeto que deba atender alguna necesidad familiar, muchas veces, imprevista. Por este motivo, debería exigirse en todas las guías docentes de criterios alternativos de puntuación que permitan, a aquellas personas que no puedan asistir con regularidad a las sesiones lectivas, compensar al $100 \%$ la puntuación perdida, reclamando la nulidad, por introducir un factor de discriminación indirecta, de cualquier otro sistema de evaluación que no tenga en cuenta estas circunstancias, pues provocaría la invisibilización, en las aulas universitarias, de los problemas de conciliación socialmente asociados al sexo femenino, impidiéndoles alcanzar la calificación final que su esfuerzo merece.

Pero no solo eso. Volviendo al tema de la maternidad y paternidad entre el alumnado universitario sorprende comprobar que, aunque la totalidad de las Universidades españolas disponen hoy en día de una guía de utilización no sexista del lenguaje y de mecanismos de prevención y detección del acoso sexual en el entorno universitario, por el momento, ninguna ha implantado protocolos específicos de actuación ante las situaciones de maternidad y paternidad del alumnado. Y es que, aunque la edad media del alumnado universitario provoque que, no sea demasiado habitual que tengan descendientes a su cargo iquiere esto decir que, el proceso biológico de la maternidad y la paternidad de este colectivo debe considerarse irrelevante a la hora de exigir el mantenimiento regular de sus obligaciones académicas? El nacimiento de un hijo, por analogía con lo que ocurre en el ámbito productivo, ¿no debería considerarse causa justificada de suspensión de las obligaciones académicas de estos estudiantes? ¿No se ha previsto ninguna fórmula de flexibilización de la carga académica en estos casos?

Resulta triste comprobar que el hecho de que no sea una situación muy habitual, coloca al sujeto que las atraviesa, en una posición de total inferioridad. Así, la total impotencia que provoca el hecho de tener que luchar individualmente contra el sistema establecido, es la que desencadena además que, la mayor parte de estudiantes que se encuentran en una de estas circunstancias (sobre todo, entre el alumnado femenino), opte por abandonar sus estudios a raíz del nacimiento. Pero no solo eso. La práctica

${ }^{15}$ Éste y otros temas, los analizan BAS PEÑA, E., FERRE JAÉN, E. y MAURANDI LÓPEZ, A. (2017), "Educación Superior, competencias transversales y género: validación de un cuestionario, Revista de humanidades, $\mathrm{n}^{\circ} .31$ (Ejemplar dedicado a: Innovación docente en el ámbito de la Universidad), págs. 5776. 
demuestra que, lo que normalmente comienza con una intención de abandono meramente temporal de la asistencia a clase, en la mayoría de los casos se transforma en un abandono definitivo de los estudios universitarios. Y si esto es así, ¿dónde está la igualdad de género en el ámbito universitario? ¿Por qué tolerar que el simple hecho del nacimiento de un hijo lastre con más fuerza la carrera académica de las universitarias mujeres que la de los hombres, comprometiendo así su futuro profesional? ¿No pueden nuestras Universidades impedir estos efectos negativos sobre el colectivo femenino?

La solución a este problema es no solo sencilla, sino también muy poco costosa: debería idearse un procedimiento en virtud del cual, si la estudiante lo desea, se produzca la suspensión de la matrícula durante el año académico en el que se produce el nacimiento del hijo, retomándose íntegramente sin coste económico alguno, de forma íntegra al año siguiente, o incluso, fraccionada a lo largo de varios cursos académicos, sin que este procedimiento se considera una segunda o tercera matrícula a efectos académicos, sino una prolongación causal de la matrícula inicial. Esta última cuestión no es un asunto baladí. No solo es que el coste de una primera, segunda o tercera matrícula es muy diferente, sino que el hecho de superar o no una asignatura en primera matrícula puede ser muy relevante a la hora de optar o mantener una beca académica, o de cara acceder a un puesto de trabajo en el que se valore la responsabilidad de los concurrentes.

Al mismo tiempo, hay una segunda cuestión que hay que tener en cuenta; si la dificultad de conciliación es la que motiva el abandono de la titulación de los estudiantes que sean padres durante el curso, ¿por qué no contrarrestar esta situación? Habida cuenta de que, hoy en día, gran parte de las Universidades españolas cuentan con una guardería universitaria, ¿por qué no convocar un mínimo de becas anuales para atender este tipo de situaciones, y beneficiar así la continuación de los estudios de alumnos y alumnas que, por lo general, no cuentan con una fuente de ingresos estable? ${ }^{16}$

\section{Cuestiones para reflexionar}

\footnotetext{
${ }^{16}$ Vaya por delante el hecho de que, como se ha adelantado, no son muchos los alumnos que, cada año, se encuentran en esta situación, parece que, estableciendo medidas de este tipo, se generaría un coste perfectamente asumible por parte de nuestras Universidades, pudiéndose incluso destinar una partida reducida a atender, anualmente, estas necesidades (por ejemplo, para financiar dos o tres plazas en la guardería), estableciéndose a su vez criterios de prelación de concurrentes (parto sobre adopción, edad, número de hijos, nota media de los estudios, ingresos anuales de la unidad familiar y, por qué no, como criterio de discriminación positiva, dando preferencia a las solicitudes planteadas por mujeres que a las formuladas por hombres).
} 
Todos los que tengan a su cargo un menor de 12 años son bien conocedores de las dificultades de conciliación que plantean los meses de julio y septiembre. ¿Cómo se compatibilizan, en cualquier ámbito profesional, los prácticamente tres meses de vacaciones escolares con una actividad profesional normal? Sin duda, esta pregunta se hace cada año en España multitud de trabajadores que han de enfrentarse a esta situación, pero cuando se trata de plantearla en el ámbito universitario ésta adquiere nuevas connotaciones. $\mathrm{Y}$ es que, ¿por qué otros docentes triplican prácticamente la duración media de las vacaciones de los restantes empleados públicos en el país, mientras que los profesores de Universidad, pese a seguir siendo socialmente considerados unos privilegiados, han perdido totalmente la facultad de disponer de los citados meses para mejorar su investigación y, de paso, aprovechar la libertad de horario que esta permite para hacer frente con mayor soltura, a sus obligaciones familiares? Los exámenes de julio y los trámites de tutorización y defensa de TFG y TFM han sido los principales artífices del endurecimiento de las condiciones de trabajo del colectivo universitario, dando lugar a unos cambios de tal intensidad que hubieran debido considerare modificaciones sustanciales de las condiciones de trabajo a los efectos previstos por el art. 41 del Estatuto de los Trabajadores, pero que, paradójicamente, se han asumido de forma pacífica por la comunidad universitaria, en aras de conseguir una hipotética (e hipócrita) mejora de la calidad de la formación de nuestros jóvenes estudiantes universitarios. Pero además de multiplicar la carga de trabajo burocrático de los docentes universitarios, y restar, como consecuencia directa, tiempo para realizar una investigación de calidad, provoca una segunda consecuencia: crea diferencias de trato injustificables entre docentes españoles, que tendrán mayor periodo de vacaciones de forma exponencialmente inversa al nivel de enseñanza en el que impartan clases. Estas nuevas obligaciones consiguen esfumar por completo las facilidades de conciliación de la vida familiar y laboral que históricamente caracterizaban a este colectivo. ¿Y es que tienen algún sentido que el periodo lectivo de las Universidades públicas comience de forma prácticamente paralela, a principios de septiembre, con los centros de educación primaria? ¿Nadie se ha percatado de que la función de guarda que realizan los centros de educación obligatoria no son para nada similares a las propias del ámbito universitario, en el que, se trata con un alumnado necesariamente mayor de edad? En otras palabras ¿por qué se olvida de nuevo que una parte igualmente importante del trabajo de un profesor universitario es su faceta investigadora y esta no tiene nada que ver con la preparación de las clases, elaboración de guías docentes, 
materiales de innovación educativa, tutorización de alumnos ni constitución de tribunales? ¿Nadie se ha dado cuenta hasta ahora de que la saturación de obligaciones obliga al profesor universitario a dedicar a la investigación un tiempo que en principio, por superar su jornada máxima diaria, hubiera debido dedicarse al descanso o al ocio? ¿Por qué no se ha tenido en cuenta todavía que, el estrés que supone hacer frente de forma simultánea a tareas muy diversas y exigentes es el principal enemigo de una investigación de calidad en las Universidades públicas? $\mathrm{Si}$ respecto a los teletrabajadores está estudiado el estrés psicosocial al que les conduce tener que responsabilizarse de tareas profesionales y familiares simultáneamente, hasta el punto de llegar a desencadenar enfermedades asociadas al trabajo ${ }^{17}$, ¿por qué se olvida que el profesorado universitario se encuentra en una situación muy parecida? Hasta que no se tome conciencia de ello, y el profesorado universitario empiece a exigir con vehemencia, una auténtica flexibilidad horaria y no un espejismo, y se racionalicen las obligaciones derivadas de la gestión meramente administrativa de títulos y asignaturas que recaen sobre los docentes, las Universidades españolas nunca podrán alcanzar el nivel de producción científica que tienen las europeas.

Otra de las cuestiones olvidadas es la función ejemplificativa que deberían tener las Universidades públicas, como centros de trabajo avanzados y respetuosos con las políticas de género, y que parece olvidada. Precisamente sobre este tema, no puede dejar de destacarse una cuestión: ¿por qué muchas Universidades públicas plantean en femenino el derecho a disfrutar del permiso para acudir a los exámenes médicos prenatales y técnicas de preparación del parto que proclama, sin distinción por género, para todos los trabajadores, el art. 37.3.f) ET? Obviamente, si la finalidad del permiso es la protección de la maternidad desde un punto de vista relacionado con la salud de las trabajadoras, su titular es la mujer embarazada, pero desde la óptica de la corresponsabilidad, que comienza con el acompañamiento de la mujer durante el embarazo y el parto, debería de poder disfrutarse por ambos progenitores, motivo por el

\footnotetext{
${ }^{17}$ Importantes cuestiones que, aunque tradicionalmente pasaban desapercibidas, en los últimos años se están empezando a poner de manifiesto. Ejemplo de ello son las distintas aportaciones doctrinales publicadas en los últimos años sobre el tema. Entre otras, véanse: CERVILLA GARZÓN, M.J. y JOVER RAMÍEREZ, C. (2015), "Teletrabajo y delimitación de las contingencias profesionales", Revista Internacional y Comparada de Relaciones Laborales y Derecho del Empleo, volumen 3, $\mathrm{n}^{\circ}$. 4, revista digital de acceso abierto, págs. 20 y ss; DÍAZ BERNARDO, L. (2014), "El teletrabajo y la seguridad y salud de los trabajadores: aplicación de la normativa específica en el domicilio del trabajador y la vigilancia y control de su cumplimiento", en AAVV, "Estudios jurídicos de aproximación del derecho latinoamericano y europeo" (dir. Acedo Penco, Á.), Dykinson, Madrid, págs. 79 y ss; o MELLA MÉNDEZ, L., "La seguridad y salud en el teletrabajo", en AAVV (2015), "Trabajo a distancia y teletrabajo: estudios sobre su régimen jurídico en el derecho español y comparado" (coord. Villalba Sánchez y Mella Méndez), Aranzadi, Pamplona, págs. 171 y ss.
} 
cual el legislador opta por redactar el citado permiso en masculino genérico. Así las cosas, ¿por qué, pese a su legalidad, razonabilidad, su oportunidad social y su escasísimo coste, algunos convenios universitarios, como el convenio colectivo para Universidades Públicas de la Región de Murcia (art. 36, BORM, 5 de abril de 2016), restringe todavía a empleadas de sexo femenino el disfrute de un derecho que el legislador, redacta en masculino genérico? ¿Por qué, en pleno siglo XXI, en un momento en el que ondea la bandera de la igualdad de género en todos los ámbitos, precisamente una Universidad pública, opta por restringir un derecho que el propio legislador contempla como general? ¿Cuál es el motivo que ha llevado a los negociadores a limitar al género femenino un derecho respecto al que el legislador utiliza el masculino genérico? ¿Tiene algún sentido equiparar la duración de la baja por paternidad a la de maternidad (como ha hecho el reciente RD-Ley 6/2019, hoy ambas denominadas suspensión del contrato por nacimiento de hijo) y en cambio restringir el derecho de los varones a disfrutar de otros permisos de duración prácticamente simbólica? Posiblemente, la criticable cláusula del convenio colectivo mencionado obedezca simplemente a un desconocimiento de la legalidad vigente unida a una falta de concienciación de los negociadores de la importancia teórica y práctica del tema, pero pese a todo, la pregunta es obligada: ¿por qué, precisamente en el entorno universitario, que muchas veces, puede considerarse la cuna de los planteamientos teóricos sobre igualdad efectiva la igualdad entre mujeres y hombres, existen defectos tan patentes? Y sobre todo, ¿por qué nadie los ha detectado y corregido hasta ahora?

Pero son más las cuestiones sobre las que se debe reflexionar. No se puede negar que existe una generalizada falta de interés en el ámbito universitario tendente a considerar las horas dedicadas a la investigación como tiempo efectivo de trabajo. Ahora más que nunca, se trata ésta de una cuestión de fundamental importancia: como es sabido, el 12 de mayo de 2019 entró en vigor la obligación de registro de jornada para la generalidad de empresas y trabajadores introducida por el reciente Real Decretoley $8 / 2019$, de 8 de marzo, de medidas urgentes de protección social y de lucha contra la precariedad laboral en la jornada de trabajo, publicado en el BOE de 12 de marzo ${ }^{18}$. De

\footnotetext{
${ }^{18}$ En general, sobre la nueva obligación de registro de jornada, véase MONREAL BRINGVAERD, E.J., “Registro de jornada: ¿era urgente y necesario implantarlo legalmente?”, Diario La Ley, n. 9390, 2019; LAHERA FORTEZA, J. (2019), "Respuestas a problemas prácticos del deber de registro diario de jornada", Observatorio de Recursos Humanos y relaciones laborales, nº. 146, págs. 46-52. Aspectos controvertidos que ya apuntaba, antes de la entrada en vigor de la nueva obligación de registro, CUBO MAYO, A. (2016), "El tiempo de trabajo y los problemas no resueltos de control y registro de la jornada y horario", Diario La Ley, no. 8819.
} 
la exposición de motivos de la citada norma se deduce que, con esta nueva medida, se pretenden conseguir que en las empresas y entidades públicas se implante un sistema efectivo de control de los tiempos de trabajo y de los descansos, facilitando a los trabajadores y a la Inspección de Trabajo la prueba sobre la realización de horas extraordinarias trabajadas pero no compensadas ni cotizadas a la Seguridad Social. En ausencia de excepción al respecto, debe entenderse que esta nueva obligación afectará a todas las empresas y entidades, independientemente del número de empleados que tengan a su servicio (siempre que tangan por lo menos uno, pues no incide sobre trabajadores autónomos), tanto si éstos se han contratado a jornada parcial o completa, de forma indefinida o temporal, si se trata de empresas privadas o de entidades públicas, del carácter especial o común de su relación laboral, o de si se ha acordado un sistema de jornada flexible o de trabajo a objetivos. Por lo tanto, en principio, y salvo que el legislador en los próximos meses introduzca alguna excepción a esta regla general, también las Universidades públicas, deberán encargarse de controlar la jornada de trabajo de sus empleados. Aunque en principio la obligación solo comprende al personal laboral, las reglas de la lógica llevan a pensar que, en el momento de establecerse estos sistemas de control, serán igualmente exigibles a todos los docentes independientemente del carácter laboral o funcionarial de su relación. Adviértase que, aunque los funcionarios no pueden realizar horas extraordinarias, si pueden recibir un plus por productividad derivado de su especial dedicación o rendimiento, lo que podría empezar a exigirse en el caso de ser implantado el nuevo registro horario.

Precisamente por lo que al ámbito universitario se refiere, conviene insistir con vehemencia en que la implantación de este nuevo sistema de control horario no está destinada a comprobar que se respetan sin irregularidades los horarios lectivos ni a garantizar un tiempo mínimo de presencia en los centros de los docentes, sino, como la propia exposición de motivos de la norma indica, a evitar que se realicen horas extraordinarias no pagadas. Así las cosas, se ha de exigir que el sistema de control horario que finalmente se implante en las Universidades sea capaz de reflejar las múltiples facetas que integran el desarrollo de las obligaciones propias del puesto: esto es, preparación e impartición de las sesiones lectivas, atención de tutorías (tanto presenciales como telemáticas), desarrollo de la investigación (con la dispersión, intermitencia, fragmentación y plurilocalización que ésta lleva aparejada) y, por supuesto, atención de las múltiples tareas de gestión, de mayor o menor nivel que en los últimos años ha florecido como apéndices inevitablemente vinculados al cumplimiento 
de las obligaciones docentes. Cualquier otro modelo de registro que no tenga en cuenta estas particularidades del personal docente será totalmente insuficiente, obviará cuestiones esenciales de su régimen jurídico y, en definitiva, minusvalorará el papel esencial que la faceta investigadora representa en la carrera universitaria.

Pero además de la dificultad de registro que conlleva necesariamente el hecho de tener que reflejar correcta e íntegramente el tiempo invertido en realizar tareas muy variadas, esta nueva obligación empresarial se enfrenta a un problema añadido: ¿somos capaces de conocer realmente cuál es el tiempo invertido en la investigación por parte de nuestro profesorado? ¿Somos conscientes de que, en muchos casos, se habrá superado la duración prevista de la jornada de trabajo marcada en la ley para los funcionarios, y en el convenio colectivo para el personal laboral? ¿Alguna vez se ha comprobado si el colectivo de profesores de Universidad disfruta íntegramente el mes de vacaciones que le reconoce la legislación vigente o si, por el contrario, lo emplea total o parcialmente en mejorar su perfil investigador, aprovechando que, temporalmente, se ha liberado de sus múltiples obligaciones docentes y administrativas? ¿El presupuesto de nuestras Universidades es capaz de asumir este nuevo gasto, abonado las horas extras realizadas? O por el contrario, ¿existe alguna fórmula para compensarlas con descanso? ¿Se va a empezar a exigir, a partir de ahora el disfrute íntegro de los tiempos de descanso, anuales, semanales y diarios, previstos en la legislación vigente, como forma de salvaguardar la salud psicosocial de este colectivo? Si esto es así, ¿existe un mecanismo realmente efectivo para poder hacerlo? Y es que, tan estricto es el nivel de exigencia que se requiere a la hora de publicar el resultado de una investigación, sea cual sea la rama de conocimiento en la que se realice, que es de prever que el sujeto en cuestión, se verá obligado a invertir un elevadísimo número de horas en llevarla a cabo, sacrificando muchas veces tiempo de sueño para poder completarla, con los inconvenientes que todo ello lleva aparejados. Existiendo obligación legal de controlar, en beneficio del trabajador, la jornada de trabajo efectivamente realizada, obviar esta exigencia no lleva más que a intensificar la carga de trabajo del profesorado universitario, a menoscabar su calidad de vida y, en definitiva, al menos por lo que atañe al tema principal de este trabajo, a dificultar todavía más las dificultades de conciliación que este trabajo tan multifuncional genera.

Por último, por lo que al alumnado se refiere, se ha de ser consciente de que, ante un mercado de trabajo cada vez más competitivo y exigente, toda formación es poca para diferenciarse del resto de concurrentes en las entrevistas de trabajo, lo que 
lleva a nuestros estudiantes a concatenar sucesivamente distintos estudios con el fin de conseguir un perfil profesional lo más completo posible. Y es entonces cuando, con el fin de permitir alcanzar tanto a hombres como mujeres, en igualdad de condiciones y con idénticas perspectivas de futuro, el citado objetivo, se ha de valorar lo siguiente ¿no deberían ser las Universidades públicas las encargadas de facilitar, para aquellos estudiantes que lo deseen, la conciliación de la vida familiar con la académica, dando ejemplo a la sociedad de lo que debería ser el nivel adecuado de protección a la familia?

Estos no son más que algunos de los muchos ejemplos que pueden encontrarse en el día a día de la actividad universitaria y que demuestran que la elevada flexibilidad de la que aparentemente disfrutan docentes y estudiantes no es más que un regalo envenenado, que en realidad lo único que ha provocado es una imperiosa necesidad de atención constante de las tareas académicas (aunque sea a través de una vía telemática), vulnerando el más elemental derecho a la "desconexión digital"19.

\section{Bibliografía}

AAVV (1996), "Mujeres y hombres en la ciencia española. Una investigación empírica", Ministerio de Trabajo y Asuntos Sociales, Secretaría General de Políticas de Igualdad, Instituto de la Mujer, Madrid.

AAVV (2016), "El principio de igualdad en la negociación colectiva", SÁNCHEZ TRIGUEROS (dir.), KAHALE CARRILLO y VELASCO PORTERO (coord.), Colección Informes y Estudios. Serie Relaciones Laborales, Ministerio de Trabajo y Asuntos Sociales, Madrid.

BAS PEÑA, E., FERRE JAÉN, E. y MAURANDI LÓPEZ, A. (2017), "Educación Superior, competencias transversales y género: validación de un cuestionario, Revista de

\footnotetext{
${ }^{19}$ Es importante tener en cuenta que no se trata ésta de una expresión coloquial con la que se intenten plasmar nuevas demandas sociales en el ámbito laboral, sino que se trata ya de un concepto jurídico, que aparece definido, aunque en términos mucho más imprecisos de lo que sería deseable, en el art. 88 de la LO 3/2018 de protección de datos personales y garantía de los derechos digitales. Adviértase que, en realidad, al reconocer expresamente el derecho a la desconexión digital de los empleados fuera de las horas de trabajo no se pretende más que reconocer el derecho del trabajador a no invertir su tiempo personal a tratar asuntos vinculados con el desarrollo de su actividad laboral, aunque esto se pueda hacer con comodidad desde el propio domicilio del trabajador, o incluso, desde el propio teléfono móvil, contestando correos electrónicos o WhatsApp. Tema que analiza con detenimiento TALÉNS VISCONTI, E.E. (2018), "La desconexión digital en el ámbito laboral: un deber empresarial y una oportunidad de cambio para la negociación colectiva", Revista de Información Laboral, nº. 4, págs. 193-208. Aunque se trata de un derecho aparentemente creado para evitar la explotación laboral de trabajadores por cuenta ajena, por analogía, debe extenderse a funcionarios y estudiantes.
} 
humanidades, $\mathrm{n}^{\mathrm{o}}$. 31 (Ejemplar dedicado a: Innovación docente en el ámbito de la Universidad), págs. 57-76.

CERVILLA GARZÓN, M.J. y JOVER RAMÍEREZ, C., (2015) "Teletrabajo y delimitación de las contingencias profesionales", Revista Internacional y Comparada de Relaciones Laborales y Derecho del Empleo, volumen 3, $\mathrm{n}^{\circ} .4$, revista digital de acceso abierto, págs. 20 y ss.

CUBO MAYO, A. (2016), "El tiempo de trabajo y los problemas no resueltos de control y registro de la jornada y horario", Diario La Ley, nº 8819.

DÍAZ BERNARDO, L. (2014), "El teletrabajo y la seguridad y salud de los trabajadores: aplicación de la normativa específica en el domicilio del trabajador y la vigilancia y control de su cumplimiento", en AAVV, "Estudios jurídicos de aproximación del derecho latinoamericano y europeo" (dir. Acedo Penco, Á.), Dykinson, Madrid, págs. 79 y ss.

GALIANA MORENO, J. M. (2015), "Apuntes sobre el tráfico laboral externo en la jurisprudencial de Tribunal Supremo"; en AAVV, "El Estatuto de los Trabajadores en la jurisprudencia del Tribunal Supremo: estudios dedicados al catedrático y magistrado Don Antonio Martín Valverde" (coord. Joaquín García Murcia, Manuel Ramón Alarcón Caracuel), Madrid, Tecnos, Capítulo III.

LAHERA FORTEZA, J. (2019), "Respuestas a problemas prácticos del deber de registro diario de jornada", Observatorio de Recursos Humanos y relaciones laborales, no. 146, 2019, págs. 46-52.

LÓPEZ ANIORTE, M.C, GARCÍA ROMERO, M.B, y FERRANDO GARCÍA, F.M. (2014), "Propuesta para la evaluación de la calidad de la investigación en el ámbito del Derecho del Trabajo y de la Seguridad Social, incluyendo una perspectiva de género", Libro resúmenes X Foro Internacional sobre la Evaluación de la Calidad de la Investigación y la Educación Superior (Coord. RAMIRO SÁNCHEZ y RAMIRO SÁNCHEZ), Ed. Universidad de Granada, Granada, págs. 100 y ss.

MEIL LANDWERLIN, G. (2011), "El uso de los permisos parentales por los hombres y su implicación en el cuidado de los niños en Europa", Revista latina de sociología, $\mathrm{n}^{\circ}$. 1, pág. 8 del soporte informático.

MELLA MÉNDEZ, L. (2015), "La seguridad y salud en el teletrabajo", en AAVV, "Trabajo a distancia y teletrabajo: estudios sobre su régimen jurídico en el derecho 
español y comparado" (coord. Villalba Sánchez y Mella Méndez), Aranzadi, Pamplona, págs. 171 y ss.

MONREAL BRINGVAERD, E.J. (2019), "Registro de jornada: ¿era urgente y necesario implantarlo legalmente?”, Diario La Ley, nº 9390.

SELMA PENALVA. A., "La discriminación por maternidad y conciliación en el ámbito universitario", FÉMERIS. Revista Multidisciplinar de Estudios de Género. Universidad Carlos III, nº. 2, Volumen 4, nº. 2, 2019, págs. 132-153.

TALÉNS VISCONTI, E.E. (2018), “La desconexión digital en el ámbito laboral: un deber empresarial y una oportunidad de cambio para la negociación colectiva", Revista de Información Laboral, $\mathrm{n}^{\circ}$. 4, págs. 193-208. 